Mental Hygiene Research. (Amer. Fourn. Psychiat., September, 193I.) Hincks, C. $M$.

The objective of mental hygiene is to assist man to adjust more effectively to a complex and dynamic environment. We cannot confine ourselves to any one mode of approach. The viewpoint of psychiatry is too specialized; it has concentrated its attention on abnormal mental conditions. Psychology must be brought into the field. Psycho-analysis has suggested profitable lines for prevention, and has clarified our conceptions of mental disorder. The active co-operation of universities must be sought in the mental hygiene movement.

M. Hamblin Smith.

Sociological Factors which Influence the Suicidal Rate. (Psyche, No. 46, October, 1931.) Wright, Maurice.

This paper, based on Durkheim's Le Suicide, supports the theory that suicide is not always evidence of mental disease, but is to a very large extent due to factors outside the individual, i.e., social factors. Durkheim's statistics show that while in most European countries the numbers of male and female insane are approximately equal, the suicide ratio is 1 woman to 4 men; that the average age of onset of insanity is 30 , while the suicide-rate increases from 20 to 80 ; again, that the Jews have the highest insanity and the lowest suicide-rate among European nations. The remainder of the paper is devoted to a description of Durkheim's suicidal types, based on sociological factors.

S. M. Coleman.

\title{
A Practical Mental Health Programme. (Psyche, No. 46, October,
} 193I.) Becker, Howard.

The author visualizes a vigorous mental hygiene organization to include the state mental hospitals, psychopathic hospitals, psychiatric wards in general hospitals, out-patient, marital, and child guidance clinics. He considers mental hygiene education indispensable for all adults, and would also have special courses of pre-parental, parental and professional education. There would be courses on personal mental hygiene in all high schools and colleges, and he lays great stress upon the inculcation of a proper mental hygiene attitude in the child at the kindergarten.

S. M. Coleman.

\section{Treatment.}

Treatment of General Paralysis. (Amer. Fourn. Psychiat., November, I93I.) Hinsie, L. E., and Blalock, F. R.

A report on the condition in 1930 of 197 general paralytics treated in 1923-26. Three methods of treatment were employed-malaria, tryparsamide, and a combination of the two. The highest remission rate $(28.4 \%)$ was in the group treated by tryparsamide alone. 